\title{
Persistent and Pernicious Errors in Algebraic Problem Solving
}

\author{
Julie L. Booth, ${ }^{1}$ Christina Barbieri,, ${ }^{1}$ Francie Eyer, ${ }^{2}$ and E. Juliana Paré-Blagoev ${ }^{2}$ \\ ${ }^{1}$ Temple University, ${ }^{2}$ Strategic Education Research Partnership Institute
}

\section{Correspondence:}

Julie L. Booth, Temple University. Email:

julie.booth@temple.edu

Keywords:

error analysis, problem solving, algebra

\begin{abstract}
Students hold many misconceptions as they transition from arithmetic to algebraic thinking, and these misconceptions can hinder their performance and learning in the subject. To identify the errors in Algebra I which are most persistent and pernicious in terms of predicting student difficulty on standardized test items, the present study assessed algebraic misconceptions using an in-depth error analysis on algebra students' problem solving efforts at different points in the school year. Results indicate that different types of errors become more prominent with different content at different points in the year, and that there are certain types of errors that, when made during different levels of content, are indicative of math achievement difficulties. Recommendations for the necessity and timing of intervention on particular errors are discussed.
\end{abstract}

Algebra I is a gate-keeper course determining for many students whether they can go on to the higher level STEM courses necessary for entrance into competitive 4-year colleges (Adelman, 2006). Despite its importance, many students in the United States fail to succeed in Algebra. For example, $61 \%$ of students score below proficient in Pennsylvania (Pennsylvania Department of Education, 2011), 64\% are less than proficient on the end-of-course Algebra I test in California (California Department of Education, 2014), and $30 \%$ of students fail in Michigan (Higgins, 2008).

The subject can be particularly challenging not only because it introduces more abstract representations and more complex relationships between quantities, but also because it can magnify the misconceptions that have their roots in earlier instruction. A variety of particularly problematic misconceptions typically plague beginning algebra students, including believing that the equals sign is an indicator of operations to be performed (Baroody \& Ginsburg, 1983; Knuth, Stephens, McNeil, \& Alibali, 2006); Chesney \& McNeil, 2014), that negative signs represent only the subtraction operation and do not modify terms (Vlassis, 2004), and that variables cannot represent more than one value (Knuth, Alibali, Weinberg, \& McNeil, 2005). Unfortunately, for many students these misconceptions persist even after typical classroom instruction (Vlassis, 2004). Unaddressed, such misconceptions affect students' success in problem solving (Knuth et al., 2005) and hinder their learning of new material (Booth \& Koedinger, 2008).

A number of interventions have been developed to target specific misconceptions. For example, there are a variety of tools designed for teaching students about the relational nature of the equals sign, including the algebra balance scale (Brown, Eade, \& Wilson, 1999; Vlassis, 2002; but see Filloy $\&$ Rojano, 1989), and a recent application using GeoGebra (Ko \& Karadag, 2013). Similarly, there is some evidence to suggest that the use of Algebra Tiles can help students understand variables and like terms (Confrey \& Lanier, 1980; Kitt \& Leitze, 1992; but see Askey, 1999); Belenky and Nokes (2009) also found that the use of manipulatives helped students correctly identify variables in algebraic word problems. As with all manipulatives, one issue is that teachers must take time to instruct students about the representations or manipulatives before they are used (Fueyo \& Bushell, 1998; Uttal, Scudder, \& DeLoache, 1997); if students are not adequately familiar with the materials, helpful tools can quickly become a hindrance (Booth \& Koedinger, 2012). Classroom time constraints must be considered when interventions are developed; even concept-based interventions which do not require familiarization with alternative representations take time. Few would argue that students' knowledge (and Algebra I success rates) would not improve if teachers could spend a class period (or more) on each prominent algebraic concept to ensure students gain a sound foundation. However, with the assessment-centered system prevalent in the United States, it seems highly unlikely that teachers could set aside a sufficient period of time to remediate each misconception.

Given the many time constraints in the classroom, knowing which common misconceptions most require targeted intervention can inform decisions about how to spend instructional time. This requires the ability to distinguish between misconceptions likely to be remediated naturally through traditional instruction and those which remain 
common throughout the year. We also need to understand which misconceptions interfere with students' performance on summative tests.

To accomplish this, we must have effective ways to measure which misconceptions are held by individual students. One method, frequently used in research studies, is to utilize written tests or interviews specifically designed to examine students' conceptual knowledge. These measures can be effective at getting an in-depth understanding of a single misconception (Lucariello, Tine, \& Ganley, 2014; Matthews, Rittle-Johnson, McEldoon, \& Taylor, 2012), or even distinguishing between several misconceptions at a given time point (Booth, Lange, Koedinger, \& Newton, 2013; Cangelosi, Madrid, Cooper, Olson, \& Hartter, 2013). Instances of these types of assessments may range from 25 minutes to measure the potential misconceptions in a single topic area for an entire class (Booth et al., 2013) to 45 minutes to measure one particular misconception in depth simultaneously for all students in a classroom (Matthews et al., 2012), to 20 minutes to interview each individual student about particular misconceptions (Cangelosi et al., 2013). Thus, for the purpose of comparing many misconceptions over a number of students over a longer period of time these methods are unlikely to be realistic for classroom use.

An alternative approach involves conducting a thorough analysis of the misconceptions demonstrated in the products students are already submitting: What types of errors are students making when they practice solving problems? This method does not take up any additional instructional time within the classroom and can be done by a teacher or researcher outside of the classroom. A number of studies have asserted that misconceptions can be effectively diagnosed from looking at student work (e.g., Clement, 1982; Corder, 1982; Liebenburg, 1997). Early work documented the 'bugs' that students made in their problem solving efforts (e.g., Payne \& Squibb, 1990), but application of an approach which tracked errors based on their source (e.g., underlying misconception) (Tatsuoka, 1983) has proven to be more effective (Birenbaum, Kelly, \& Tatsuoka, 1992). Cangelosi and colleagues (2013) surmised that where persistent errors exist, the student may be stalled at a low level of development for the associated concept. Consistent with this, misconceptions (as measured by conceptual measures like those described above) have been found to directly predict the types of errors students will make when solving problems (Booth \& Koedinger, 2008). Nesher (1987) perhaps said it best when she called errors the "beacons ... that mark for us the constraints and limitations of our knowledge (p. 37)."

Thus, determining which errors are most persistent and pernicious in Algebra I can help focus the attention of both researchers and practitioners towards developing and utilizing interventions to remediate misconceptions at the most critical and effective times. Previous work on algebraic misconceptions has identified many common errors in algebra (e.g., Warren, 2003; Vlassis, 2008; Knuth et al., 2005) and there have been highly useful efforts to classify these common misconceptions and errors (Kieran, 2007; Bush \& Karp, 2012). However, few studies examine more than one type of misconception. In a notable exception, Cangelosi and colleagues (2013) find that negative sign errors persist beyond other types of errors for students enrolled in College Algebra through Calculus II. In another instance, middle school students misconceptions about the equals sign and negative sign were both found to be problematic for learning to solve algebraic equations (Booth \& Koedinger, 2008). Finally, one study of Malaysian pre-algebra students examined the relative frequency of a variety of errors made when simplifying expressions; order of operations and negative sign errors were among the most prevalent (Seng, 2010). More work like this must be conducted, perhaps especially with middle school Algebra students, to directly compare the prevalence and negative influence of different errors. This is the focus of the present study.

\section{THE PRESENT STUDY}

In the present study, we examine six categories of conceptual errors in students' problem solving work in algebra: Errors indicating misunderstanding of the concepts of variables, negative sign, equality/inequality, operations, fractions, and mathematical properties. For comparison, we also consider the prevalence errors made in carrying out arithmetic. The present study answers three primary research questions. First, it aims to determine which of these types of errors are most common within a variety of topics covered in Algebra I. It stands to reason that certain types of errors might be present in one topic and not another. For instance, errors involving equality/inequality or variables are unlikely to occur when students are just practicing carrying out the order of operations in arithmetic expressions, as variables and equals signs are not central to those problems. Equality/inequality and variable errors are thus more likely to emerge in topics involving solving equations or inequalities. Other types of errors, such as those involving a negative sign or operations, may be more prevalent in each topic, as it is necessary to handle negative signs and carry out operations throughout the curriculum.

The second purpose is to identify which are the most persistent errors students make while solving problems across Algebra I. Are there certain errors that are more common in one part of the year than another? For instance, certain types of errors which are strongly tied to concepts covered prior to Algebra, such as operations, fractions, and mathematical properties, may be more prevalent early in the year but taper off as students regain their footing with the relevant content. Other types of errors, such as equality/inequality, variables, and negative sign, which are tied more closely to algebraic 
Table 1.

Description of topics and sample items

\begin{tabular}{|c|c|c|}
\hline Topic & Description & Sample Items \\
\hline $\begin{array}{l}\text { Order of } \\
\text { Operations }\end{array}$ & $\begin{array}{l}\text { Students demonstrate knowledge of the prece- } \\
\text { dence of completing one operation over another } \\
\text { while simplifying a mathematical expression. }\end{array}$ & $\begin{array}{l}\text { Find the value of each expression. Show each } \\
\text { step. }\end{array}$ \\
\hline $\begin{array}{l}\text { Solving } 1 \text { - and } \\
\text { 2-step Equations }\end{array}$ & $\begin{array}{l}\text { Students solve equations that require only one or } \\
\text { two operations be completed. }\end{array}$ & Solve each equation: \\
\hline $\begin{array}{l}\text { Solving Multi-Step } \\
\text { Equations }\end{array}$ & $\begin{array}{l}\text { Students solve equations that require more than } \\
\text { two operations be completed. }\end{array}$ & Solve each equation. Show all of your work. \\
\hline $\begin{array}{l}\text { Systems of } \\
\text { Equations }\end{array}$ & $\begin{array}{l}\text { Students find the values of a set of unknowns } \\
\text { that satisfy a pair of equations using substitution } \\
\text { or elimination. }\end{array}$ & $\begin{array}{l}\text { Solve the system of equations using the linear } \\
\text { combination (elimination) method. Show all of } \\
\text { your work. }\end{array}$ \\
\hline Inequalities & $\begin{array}{l}\text { Students graph an unequal relationship between } \\
\text { values on number lines, write out mathemati- } \\
\text { cal sentences from number lines displaying the } \\
\text { inequality, and simplify inequality sentences. }\end{array}$ & Solve the inequality. Show all of your work. \\
\hline $\begin{array}{l}\text { Multiplying } \\
\text { Polynomials }\end{array}$ & $\begin{array}{l}\text { Students multiply polynomials or expressions with } \\
\text { two or more algebraic terms including variables } \\
\text { raised to a power and multiplied by a coefficient. }\end{array}$ & Find the product. Show all of your work. \\
\hline
\end{tabular}

Note. Students completed 12 problems ranging in difficulty for each topic.

concepts may occur more frequently as more difficult content is introduced. Arithmetic errors, which are not at all tied to algebraic content and may perhaps be more indicative of attention to detail or fact memorization rather than conceptual understanding, may be equally prevalent across the year.

Finally, we aim to determine which of the conceptual (e.g., non-arithmetic) errors made at different points in the year are most pernicious. That is, which of the errors at which time points (beginning, middle, or end of year) are most predictive of students' difficulty when performing skills measured on standardized tests? It could be that errors identified as most persistent are also the most problematic, in which case there is a clear case for remediating the associated misconceptions early and often. However, it is also possible that certain errors are more troublesome when made at one point of the year as compared to another; for instance, it seems likely that making errors related to a particular concept is harmless when the concept is first introduced, but more problematic if students continue to make those errors later in the school year. In these cases, intervention at particular time points may be critical for improving algebra success.

\section{METHODS}

\section{PARTICIPANTS}

Across five school districts, 565 students (259 male, $298 \mathrm{fe}$ male, 8 unspecified) enrolled in non-honors Algebra I courses participated in the study, using the curriculum specified by their district. The school districts came from four states: Illinois, Ohio, Virginia, and Wisconsin. In total, there were four different texts used for instruction: Larson, Boswell, Kanold, and Stiff (2007, used by District 1 and by District 5's high schools); Leiva and Brown (1997, used by District 2 and District 3); Murdock, Kamischke, and Kamischke (2007, used by District 4); and Cummins, Malloy, McClain, Mojica, and Price (2006, used by District 5's middle schools). The ethnicity of participating students was 34\% Caucasian, 31\% Black, 23\% Hispanic, $10 \%$ Asian, and $2 \%$ biracial or of another race. Using eligibility for free or reduced lunch as a proxy, approximately $43 \%$ of participants were classified as low-SES. A total of 37 Algebra I classes, taught by a total of 29 teachers in 13 schools, were included in the study. Thirty-five percent of the students attended a middle school and were enrolled in grades 7 or 8 ; the remaining $65 \%$ were high school students in grades 9 or 10 .

\section{MEASURES}

Two types of measures were utilized in the study: Assignments given during the school year and an assessment given at the end of the school year (EOY).

\section{Assignments}

Data consist of the students' work on assignments from six topics over the course of the school year: Order of Operations (September), Solving 1- and 2-step Equations (October), Solving Multi-Step Equations (November), Systems of Equations (January), Inequalities (February), and 


\section{Table 2.}

\section{End of year assessment items sampled from standardized achievement tests}

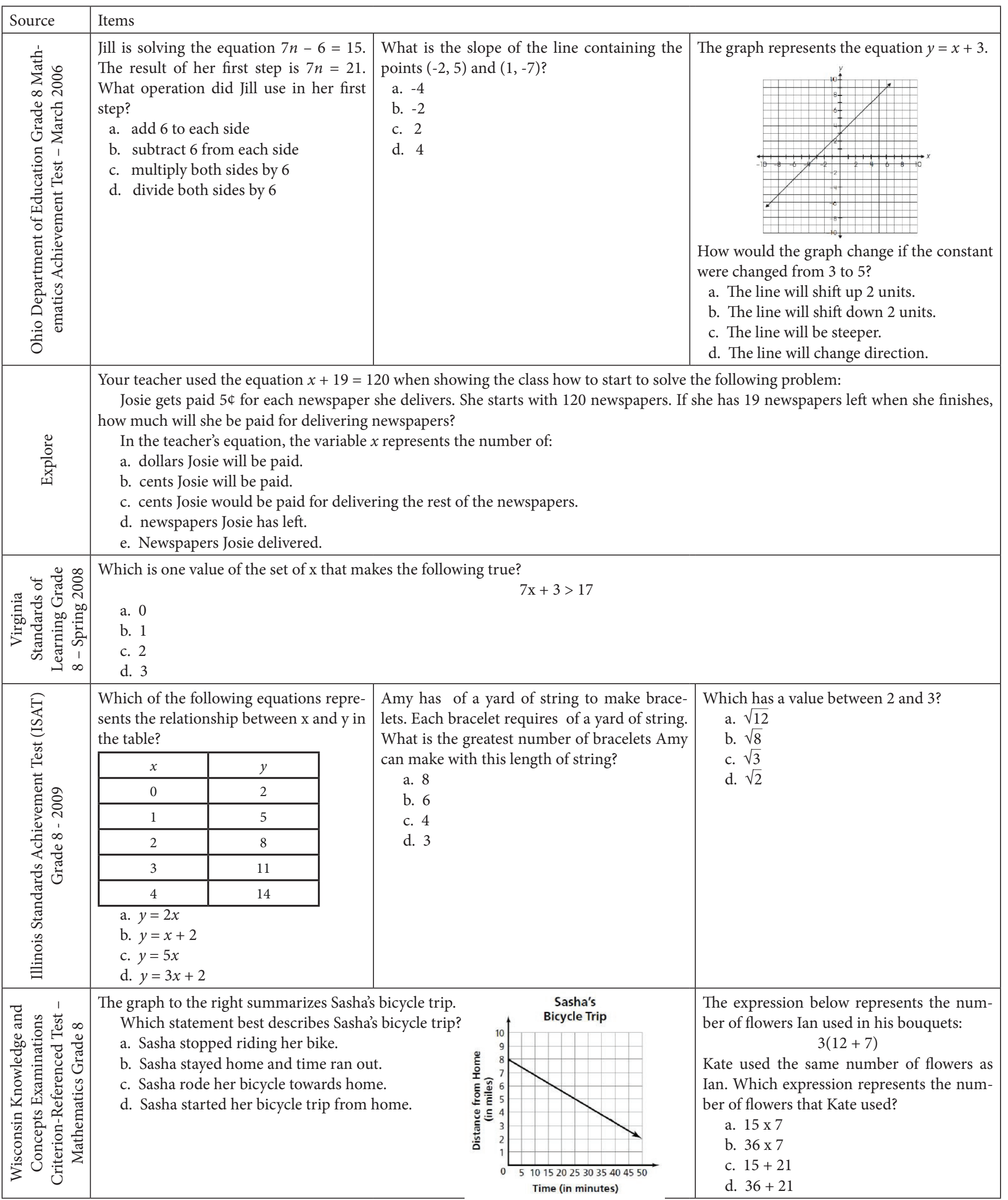


Polynomials (April). Each assignment consisted of 12 problems for students to solve. The assignments were created by the research team as control assignments for a larger study; each control assignment was designed to be compatible with all of the curricula used by the participating school districts and utilized problems that were isomorphic to those in the textbooks. A description of the topic as well as sample items from each assignment can be found in Table 1.

\section{EOY assessment}

At the end of the school year (EOY), students were administered a paper-and-pencil test consisting of 10 Algebra-related released items taken from the five standardized tests used by the participating districts: Ohio Achievement Test-Grade 8 (3 items; Ohio Department of Education, 2006); Standards of Learning Test-Grade 8 Mathematics (1 item; Virginia Department of Education, 2008), Illinois Standards Achievement Test-Grade 8 Math (3 items; Illinois State Board of Education, 2009), Wisconsin Knowledge and Concepts Examination-Grade 8 Mathematics (2 items; Wisconsin Department of Public Instruction, 2006), and the EXPLORE test (1 item; ACT, Inc., 2014). Eighth grade test items were used because they were closest to Algebra I content and because the next testing grade level available $\left(11^{\text {th }}\right)$ was higher than that of any participating student. Particular items were chosen for their relevance to Algebra I curriculum topics; see Table 2 for a list of the items used and their sources. For each

\section{Table 3.}

Categories and descriptions of conceptual errors by topic

\begin{tabular}{|c|c|c|c|c|c|c|c|}
\hline Error category & Specific errors & 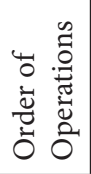 & 站 & 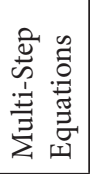 & 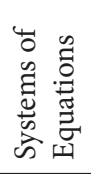 & $\begin{array}{l}\stackrel{\mathscr{\Xi}}{:} \\
\stackrel{\Xi}{\Xi} \\
\stackrel{\Xi}{\Xi} \\
\stackrel{\Xi}{\Xi}\end{array}$ & 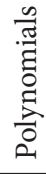 \\
\hline \multirow{2}{*}{ Variable } & Combining unlike terms; moving, deleting, or adding a variable & $\mathrm{x}$ & $\mathrm{x}$ & $\mathrm{x}$ & $\mathrm{x}$ & $\mathrm{x}$ & $\mathrm{x}$ \\
\hline & Solving for only one variable & -- & -- & -- & $\mathrm{x}$ & -- & -- \\
\hline \multirow[t]{2}{*}{ Negative Sign } & $\begin{array}{l}\text { Moving, deleting, or adding a negative sign, including subtracting } \\
\text { when addition is indicated or addition when subtraction is indicated. }\end{array}$ & $\mathrm{x}$ & $\mathrm{x}$ & $\mathrm{x}$ & $\mathrm{x}$ & $\mathrm{x}$ & $\mathrm{x}$ \\
\hline & Moving a term without changing its sign & -- & $\mathrm{x}$ & $\mathrm{x}$ & $\mathrm{x}$ & $\mathrm{x}$ & -- \\
\hline \multirow{2}{*}{$\begin{array}{l}\text { Equality/ } \\
\text { Inequality }\end{array}$} & $\begin{array}{l}\text { Moving, deleting, or adding an equals sign; performing operations with- } \\
\text { out maintaining balance on both sides of the equals or inequality sign }\end{array}$ & $\mathrm{x}$ & $\mathrm{x}$ & $\mathrm{x}$ & $\mathrm{x}$ & $\mathrm{x}$ & $\mathrm{x}$ \\
\hline & $\begin{array}{l}\text { Changing/not changing the direction of the inequality sign when } \\
\text { inappropriate }\end{array}$ & -- & -- & -- & -- & $\mathrm{x}$ & -- \\
\hline Operation & $\begin{array}{l}\text { Performing addition or subtraction when multiplication or divi- } \\
\text { sion is indicated, or vice versa. }\end{array}$ & $\mathrm{x}$ & $\mathrm{x}$ & $\mathrm{x}$ & $\mathrm{x}$ & $\mathrm{x}$ & $\mathrm{x}$ \\
\hline \multirow{2}{*}{$\begin{array}{l}\text { Mathematical } \\
\text { Property }\end{array}$} & Inappropriately applying the commutative or associative property & $\mathrm{x}$ & $\mathrm{x}$ & $\mathrm{x}$ & $\mathrm{x}$ & $\mathrm{x}$ & $\mathrm{x}$ \\
\hline & Inappropriately applying the distributive property & -- & -- & $\mathrm{x}$ & $\mathrm{x}$ & $\mathrm{x}$ & $\mathrm{x}$ \\
\hline Fraction & $\begin{array}{l}\text { Moving a term from the numerator to the denominator or vice } \\
\text { versa; performing multiplication when division is indicated by the } \\
\text { fraction bar; using addition or subtraction to eliminate a numera- } \\
\text { tor or denominator }\end{array}$ & $\mathrm{x}$ & $\mathrm{x}$ & $\mathrm{x}$ & $\mathrm{x}$ & $\mathrm{x}$ & $\mathrm{x}$ \\
\hline
\end{tabular}

Figure 1.

Example coding of multiple errors in a single problem response. In his first step, the student 1) subtracts $4 x$ when the $4 x$ is already negative (negative sign error), and 2) subtracts the $4 x$ twice from the same side of the equation (equality/inequality error). Then, he when subtracting the $-4 x$ from the $-6 x$, he ignores the negative sign he added and computes the sum as $-2 x$ (negative sign error). Thus, in a single problem, this student made two negative sign errors and one equality/inequality error.

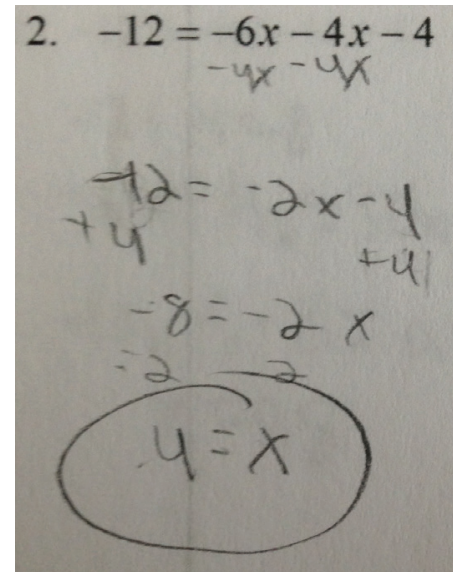

student, the percentage of problems they answered correctly on the EOY test was computed.

\section{PROCEDURE}

As control participants in a larger intervention study, these students completed practice assignments throughout the 
Table 4.

Sample student work demonstrating each conceptual error category

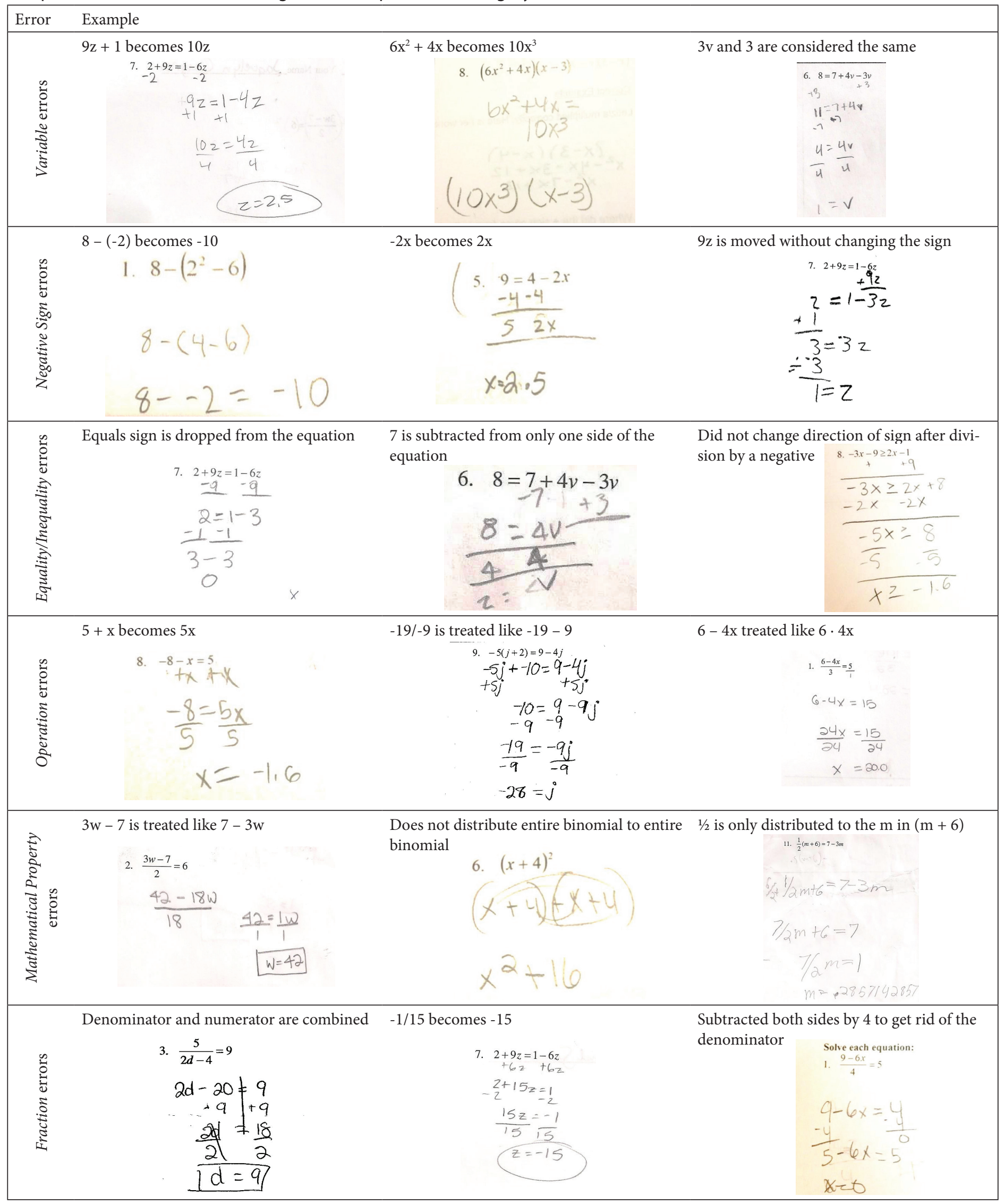


school year. Teachers could decide which assignments to use and when to use them as consistent with their syllabus, curriculum, and state standards. Although all assignments were not used by all teachers in the study, those assignments that were used were completed in the same order as listed previously. Assignments were used for practice in class or as homework, as deemed appropriate by the classroom teacher. During a class period at the end of the school year, teachers administered the EOY assessment to all students.

\section{CODING}

Student work on the six practice assignments was coded in terms of six types of conceptual errors made while solving the problems: Variable errors, Negative Sign errors, Equality/ Inequality errors, Operation errors, Mathematical Property errors, and Fraction errors. A single coder was utilized for all of the date to ensure consistency across assignment topics. Table 3 illustrates the categories of conceptual errors subsumed in the category for each topic area. Table 4 presents student work samples demonstrating examples of each type of conceptual error. In addition to the six conceptual errors, student work was coded for Arithmetic errors (computing an arithmetic calculation inaccurately, e.g., $5+7=11 ; 4 / 8=3$ ) made during problem solution. As demonstrated in Figure 1 , student work for a single problem - or even a single step within a problem-could be classified as having multiple errors, but each individual instance of a mistake was only classified into one error type. The number of each type of error made on each topic was computed for each student.

We also computed the average number of each type of error made in each trimester, beginning vs. the middle vs. the end of the year, which reflects the frequency of each error type on easy vs. moderate vs. harder content. Beginning of year assignments were order of operations and 1- and 2-step equations. Middle assignments were multi-step equations and systems of equations. End assignments were Inequalities and Polynomials. If students did not complete one of the two assignments in that trimester, the frequency of each error made on the other assignment was used as the score for that trimester.

\section{RESULTS}

Figure 2 shows the frequency of each error type made on each assignment topic. Note that because individual teachers could decide whether or not to use a particular assignment, the number of students varied for each topic. To determine which types of errors were most common within each topic area, we conducted a series of Repeated Measures ANOVAs, one for each topic, on the number of each error category made on that topic's assignment; the data were also analyzed by estimating a Bayes factor using Bayesian Information Criteria (Wagenmakers, 2007), which compares the fit of the data under the null hypothesis with that for the alternative hypothesis. Significant main effects of error category were found for each topic, indicating that the frequency of different types of errors varied within each topic. Results are reported in Table 5.

Follow-up paired-sample t-tests with Bonferroni corrections were conducted on each pair of error types within a topic. As shown in Figure 2, the most common errors for the Order of Operations assignment were arithmetic errors and negative sign errors. For 1-step equations, the most frequent were negative sign errors followed by fractions errors. For Multi-step equations, negative sign errors were most common followed by fractions and arithmetic errors. For Systems of equations, negative sign errors were most common, followed by variable and arithmetic errors. For Inequalities, the most frequent were Equality/Inequality errors followed by negative sign errors. Finally, for Polynomials, the most frequent errors were those with variables followed by negative sign errors.

To determine which types of errors are most persistent over the course of Algebra I content, we conducted a 3 (trimester: beginning vs. middle vs. end) x 7 (error type) Repeated Measures ANOVA. Mauchly's test of sphericity

Table 5.

RM ANOVA comparing errors by topic.

\begin{tabular}{|c|c|c|c|c|}
\hline Topic & $F$ & $d f$ & $\boldsymbol{\eta}_{p}^{2}$ & $\mathrm{BF}$ \\
\hline Order of Operations & $118.23^{\star * *}$ & $(6,2904)$ & .20 & $1.18 \times 10^{-15}$ \\
\hline 1- step equations $\mathrm{s}^{\mathrm{a}}$ & $265.03^{* * *}$ & $(2.06,913)$ & .37 & $3.13 \times 10^{-44}$ \\
\hline Multi-step equations ${ }^{\mathrm{a}}$ & $173.79^{* * *}$ & $(2.88,1333.82)$ & .27 & $5.16 \times 10^{-29}$ \\
\hline Systems of equations ${ }^{\mathrm{a}}$ & $189.54^{\star * *}$ & $(3.18,1036.14)$ & .37 & $2.85 \times 10^{-29}$ \\
\hline Inequalities $^{\mathrm{a}}$ & $281.00^{* * *}$ & $(6,2484)$ & .40 & $1.49 \times 10^{-39}$ \\
\hline Polynomials & $105.12^{* * *}$ & $(6,2502)$ & .20 & $2.88 \times 10^{-13}$ \\
\hline
\end{tabular}




\section{Figure 2.}

Frequency of each type of error within each assignment topic

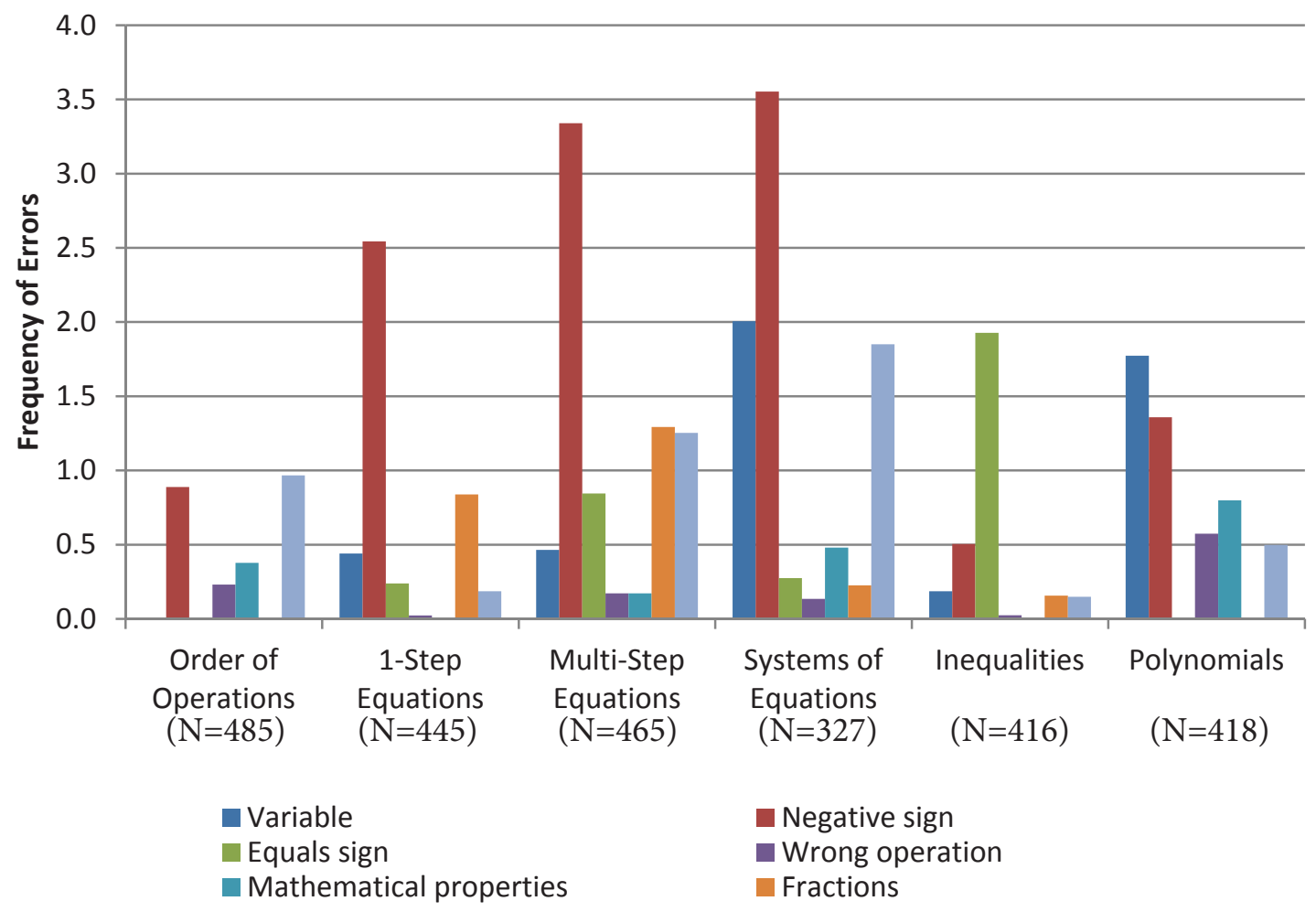

Figure 3.

Frequency of each error type during each trimester

\section{Types of Errors by Trimester}

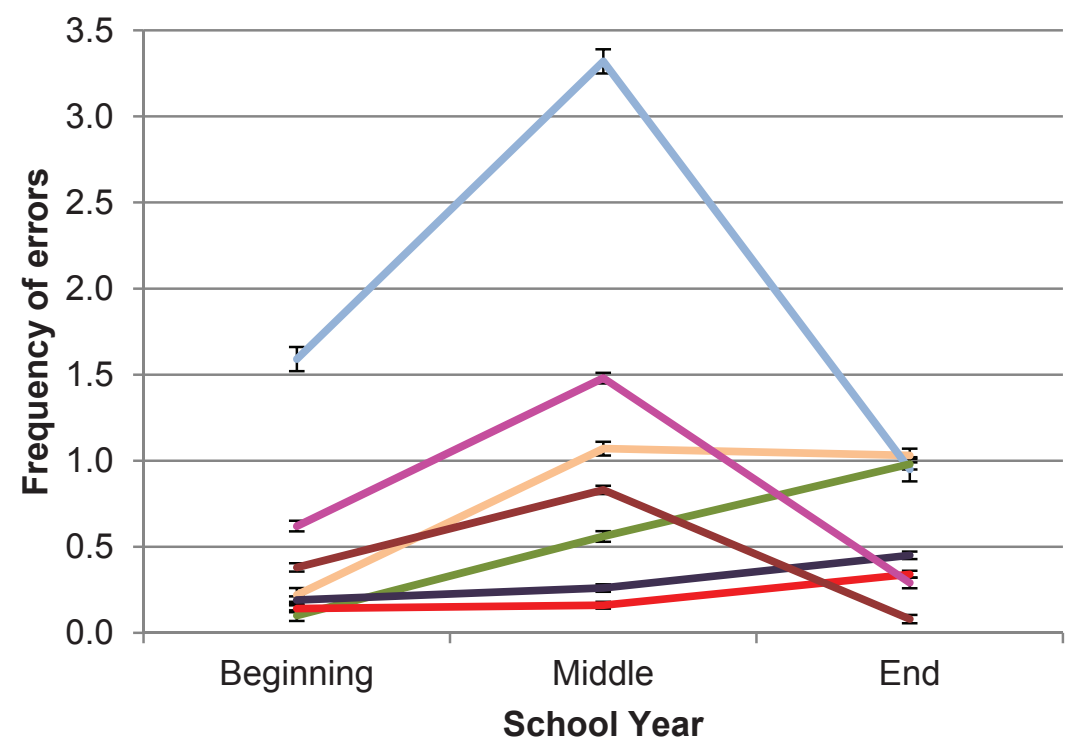

Variable

Negative

Equals sign

Wrong operation

Mathematical properties

Fraction

Arithmetic

Note: Error bars indicate standard errors.

indicated violations of the sphericity assumption so degrees of freedom were adjusted using Greenhouse-Geisser corrections for main effects of error type and trimester as well as the interaction between error type and trimester. The analysis yielded a significant main effect of error type, $F(3.12$, $1367.99)=317.31, p<.001, \eta_{\mathrm{p}}^{2}=.42$. An estimated Bayes factor (null/alternative) suggested that the data were $1.52 \times 10^{-48}: 1$ in favor of the alternative hypothesis, or rather, $6.58 \times 10^{47}$ 
Table 6.

Correlations between EOY score and each type of error for each topic.

\begin{tabular}{|c|c|c|c|}
\hline & Beginning & Middle & End \\
\hline Variable & $-.18^{\star * *}$ & $-.18^{\star * *}$ & -.08 \\
\hline Negative Sign & $-.18^{\star * *}$ & $-.14^{\star * *}$ & $-.19^{\star * *}$ \\
\hline Equality/Inequality & $-.09^{*}$ & $-.17^{\star * \star}$ & $-.17^{\star \star *}$ \\
\hline Wrong Operation & $-.16^{\star * *}$ & $-.16^{\star * \star}$ & -.08 \\
\hline $\begin{array}{l}\text { Mathematical } \\
\text { Property }\end{array}$ & $-.17^{\star * *}$ & $-.10^{*}$ & -.07 \\
\hline Fraction & -.02 & -.01 & $-.15^{\star * \star}$ \\
\hline Arithmetic & $-.10^{*}$ & $-.11^{\star *}$ & $-.18^{\star * \star}$ \\
\hline
\end{tabular}

Table 7.

Predictors of end of year (EOY) assessment.

\begin{tabular}{|c|c|c|c|}
\hline & $\beta$ & $B$ & $S E$ \\
\hline Equality/Inequality Errors: 1st trimester & -.07 & -.04 & .03 \\
\hline Equality/Inequality Errors: 2nd trimester & $-.17^{\star * \star}$ & $-.03^{\star * \star}$ & .01 \\
\hline Equality/Inequality Errors: 3rd Trimester & $-.15^{\star * *}$ & $-.03^{\star \star \star}$ & .01 \\
\hline Negative Sign Errors: 1st trimester & -.05 & -.01 & .01 \\
\hline Negative Sign Errors: 2nd trimester & .03 & .00 & .00 \\
\hline Negative Sign Errors: 3rd Trimester & $-.08^{\dagger}$ & $-.01^{\dagger}$ & .01 \\
\hline Variable Errors: 1st trimester & $-.10^{*}$ & $-.04^{*}$ & .02 \\
\hline Variable Errors: 2nd trimester & -.03 & .00 & .01 \\
\hline Mathematical Property Errors: 1st trimester & $-.10^{*}$ & $-.04^{*}$ & .02 \\
\hline Mathematical Property Errors: 2nd trimester & $-.09^{*}$ & $-.04^{*}$ & .02 \\
\hline Wrong Operation Errors: 1st trimester & $-.09^{\dagger}$ & $-.04^{\dagger}$ & .02 \\
\hline Wrong Operation Errors: 2nd trimester & $-.08^{\dagger}$ & $-.04^{\dagger}$ & .02 \\
\hline Fraction Errors: 2nd trimester & -.04 & -.03 & .04 \\
\hline Arithmetic Errors: 1st trimester & -.02 & -.01 & .01 \\
\hline Arithmetic Errors: 2nd trimester & .00 & .00 & .01 \\
\hline Arithmetic Errors: 3rd trimester & $-.11^{\star *}$ & $-.05^{\star \star}$ & .02 \\
\hline$R^{2}$ & \multicolumn{3}{|l|}{.216} \\
\hline$F$ & \multicolumn{3}{|l|}{$7.27^{\star * *}$} \\
\hline
\end{tabular}

times more likely to occur under a model including an effect of error type, rather than a model without it. Follow-up pairedsamples t-tests with Bonferroni corrections demonstrated that the frequency of errors across all topics and trimesters in descending order was as follows: negative sign errors $(M=1.96)$, arithmetic $(M=.80)$ and variable errors $(M=.77)$, equals sign errors $(M=.55)$, fraction errors $(M=.43)$, mathematical properties errors $(M=.30)$, and wrong operation errors $(M=$ $.21)$. Contrasts were significant at the $p<.001$ level with the exception of arithmetic and variable errors which were not significantly different from each other. The main effect of trimester was also significant, $F(1.66,727.28)=141.79, p<.001$, $\eta_{\mathrm{p}}{ }^{2}=.25$; the estimated Bayes factor suggested the data were 2.96 $\mathrm{x} 10^{-25}: 1$ in favor of the alternative hypothesis, or $3.37 \times 10^{24}$ times more likely to occur under a model including an effect of trimester. Follow-up paired-samples t-tests with Bonferroni corrections revealed significant differences in the number of errors made between all three trimesters $(p<.001)$. Frequency of errors in ascending order was as follows: beginning of the year $(M=.46)$, end of the year $(M=.59)$, and middle of the year 
$(M=1.10)$. The interaction between error type and trimester was also significant, $F(6.13,2683.66)=106.64, p<.001, \eta_{\mathrm{p}}{ }^{2}=.20$; the estimated Bayes factor suggested the data were $2.13 \times 10$ ${ }^{13}: 1$ in favor of the alternative hypothesis, or 470 billion times more likely to occur under a model including an interaction between error type and trimester. To interpret the interaction, we calculated simple effects with separate Repeated Measures ANOVAs on trimester, one for each error type. As shown in Figure 3, negative sign, fraction, and arithmetic errors were most prevalent in the middle of the school year, followed by the beginning, and then the end of the year (all $p s<.001$ ). In contrast, equals sign, wrong operation, and mathematical properties errors were most common at the end of the school year. Variable errors were equally prevalent in the middle and end of the school year.

To determine which types of errors are most problematic for student performance on standardized test items, we first correlated each of the error types in each trimester with student scores on the EOY test. As shown in Table 6, sixteen error/trimester combinations were significantly negatively correlated with EOY test scores, suggesting that as instances of each error increased, student EOY scores decreased.

To determine which of those sixteen error/trimester combinations were most pernicious, we regressed EOY scores on the number of each type of error made for each trimester in which the correlation was significant. Results are presented in Table 7. Nine factors emerged as independent predictors of EOY scores: making more variable errors at the beginning of the year (on simpler content), making more mathematical property and wrong operation errors at the beginning and middle of the year (on simple and moderate content), making more equality/inequality errors in the middle and end of the year (on increasingly more difficult content), and making more negative sign and arithmetic errors at the end of the year (on difficult content) all predict lower EOY test scores.

\section{DISCUSSION}

Results from this study suggest that, while students make a variety of conceptual errors when solving algebra problems over the course of the school year, there are some interesting patterns in the types of errors they make, when they make them, and how problematic they are. For instance, negative sign errors were by far the most prominent during the school year as a whole, and they were consistently prominent across each of the six topics in the study. Negative sign errors seem to be most prevalent in the middle of the school year, when students are learning to solve more complex equations or systems of equations. Of course, the frequency of the error is not necessarily a reason for concern; it is important to note that if students make these errors during the beginning or middle of the school year, it is not yet indicative of difficulty achieving in mathematics. This suggests that intervention on negative sign errors earlier in the school year beyond what is done in typical instruction may not be necessary, even though they are occurring frequently. There is more reason for concern with the students who are still making many negative sign errors towards the end of the year. Intervention and conceptual remediation may be necessary to help these students succeed in algebra. A surprisingly limited amount of research has been conducted on students' understanding of negative numbers (Kieran, 2007), however, the use of number lines and set models may help students to develop a stronger understanding (Altiparmak \& Özdoğan, 2010; Ashlock, 2006); this suggestion is consistent with the recommendation to model with mathematics in the Common Core State Standards for Mathematics (NGA \& CCSSO, 2010).

Equality/inequality errors tend to emerge as students gain more experience solving equations (or inequalities), and continue to increase through the end of the school year. Consistent with this pattern, making equality/inequality errors during either the middle or end of the year-when they are becoming more prominent-is a troublesome sign for students' math achievement. Perhaps this is not surprising, given that the notion of balance across two sides of an equation is one of the most foundational concepts underlying algebra and that students have difficulty moving from an operational to a relational understanding of the equals sign (e.g., Chesney \& McNeil, 2014). Perhaps having an operational understanding is sufficient for performance on simple equations, but the lack of a relational understanding becomes more problematic when students face more complex equations. Results from this study suggest that any classroom time devoted to improving students' conceptual understanding of the equals sign is likely well spent; fortunately, a variety of tools, materials, and instructional suggestions are already available for this purpose, including utilizing a balance scale (Vlassis, 2002) or introducing arithmetic sentences that are in unconventional forms, such as $7=2+5$, etc. (McNeil, Fyfe, Petersen, Dunwiddie, \& Brletic-Shipley, 2011).

Two types of errors dealing with more basic arithmetic concepts are those involving performing the wrong operation, and those violating mathematical properties of number. Neither of these is among the most prominent errors made in any of the six topics. However, students who begin the year making these errors are more likely to struggle to achieve in mathematics. This is not surprising as both concepts have their root in the lessons they have been taught since the beginning of their school career. Based on the Common Core State Standards for Mathematics which, for these topics, broadly mirror the timelines that were likely in place when these data were collected, students begin working with addition and subtraction as early as kindergarten, and continue 
on to multiplication and division by third grade (NGA \& CCSSO, 2010). By the time students complete elementary school, they are to be fluent in basic facts with all four operations, and should have begun using those operations to complete computations with whole numbers, decimals, and fractions (NGA \& CCSSO, 2010). Similarly, students begin working with the commutative and associative properties of addition in first grade. By third grade they are using the commutative and associative properties of multiplication and learning the distributive property (NGA \& CCSSO, 2010). If students begin algebra still misunderstanding these operations and properties they have been practicing for years, they clearly should have difficulty achieving in algebra. Warren (2003) suggests that these misconceptions persist because students are not provided with enough time to explore the number and operation systems prior to middle school; these types of misunderstandings can be cleared up in elementary school by having students justify their use of properties of numbers, similar to how it is done in geometry proofs (Carpenter, Levi, \& Farnsworth, 2000). Further research is needed to determine whether remediation of these basic concepts is effective during algebra courses, or if these concepts should be heavily reinforced in earlier years for students who demonstrate relevant misconceptions.

Variable errors appear to increase toward the middle and end of the year, when students are dealing with more complex equations. However, it is those made at the beginning of the year, when students are just learning to solve simple equations, that are indicative of difficulty in math achievement. This may indicate that making variable errors when there are many components to juggle within an equation is understandable and indicative of a student with average ability. However, making variable errors when there is only one variable to work with might be indicative of a student who is lacking a key understanding of variables that will be an obstacle in progressing in algebra. This suggests that ensuring students develop a sound understanding of the concept of variables, particularly their understanding of which terms are 'like' and which are 'unlike', could be a good candidate for intervention in the beginning of algebra courses. Effective instructional techniques for this purpose include using representations such as tables and area models to represent algebraic expressions (Swan, 2000; Ross \& Willson, 2012). Additionally, researchers suggest providing experience with software that allows them to manipulate visual objects without using algebraic symbols (Yerushalmy, 1997), perhaps like the increasingly popular app DragonBox Algebra 5+ (WeWantToKnow, 2012).

Interestingly, though fraction errors were prominent, especially in the middle of the year, they were not indicative of difficulty on our math achievement measure. This is surprising, given that fraction knowledge has been shown to be highly predictive of future math achievement (Siegler et al.,
2012), critical for algebra readiness (Booth \& Newton, 2012), performance, and learning (Booth, Newton, \& Twiss-Garrity, 2014), and is hypothesized to be one of the most important factors in algebra achievement (NMAP, 2008). One reason for the apparent discrepancy may be that scholars have identified foundational knowledge of the magnitudes of fractions, and the understanding of fractions as numbers, as the critical knowledge components impacting algebra (e.g., Booth et al., 2014; Empson \& Levi, 2011). In the present study, fraction errors do not represent students' misunderstanding of the values of fractions themselves, but their misunderstanding of the relationships between the numerators and denominators. Still, it is surprising that this misunderstanding is not detrimental to achievement in the present study. Ongoing work on the relationship between fraction knowledge and algebra achievement might directly test whether students' understanding of the components of fractions contributes at all beyond that of the magnitudes of fractions as a whole.

Finally, arithmetic errors, though not indicative of any type of misconception, are quite prominent, and were most prevalent in the middle of the school year, when students are learning to solve more complex equations or systems of equations. Again, frequency of errors is not necessarily reason for concern; indeed, making frequent arithmetic errors at the beginning and middle of the school year is not indicative of difficulty with mathematics achievement. Instead, it is arithmetic errors being made at the end of the school year, on the most difficult content, that is reason for concern. It is also interesting to note that despite the prominence of arithmetic errors, many conceptual errors emerge as predictors of difficulty with mathematics achievement above and beyond that of arithmetic errors, again reinforcing that the frequency of an error alone should not be used to determine how concerning that error might be. While results regarding arithmetic errors do not suggest the necessity of any conceptual remediation, they may indicate that students who make many careless mistakes might require a different sort of intervention to reinforce basic arithmetic facts or to help them focus on the task at hand.

One obvious limitation of this study, though critical for practical implementation in real-world classrooms, is that students completed certain assignments at certain points in the school year, when relevant for their curriculum. Thus, it is not clear whether making an error at the beginning of the year is necessarily indicative of a carryover misconception from prior years or if certain types of content in the context of certain curricula are more likely to elicit certain types of errors. Truly teasing apart the effect of time of year from the effect of assignment topic would require administration of the same assignment (or assignment type, at least) at multiple points in the school year. Further, it would be interesting to compare the likelihood of errors across curricula. It is also critical to note 
that a given error may be indicative of more than one misconception. For example, if a student moves a term without changing its sign, they may not understand the meaning of the negative sign, but they may also have difficulty understanding the relational nature of the equals sign and how the operations completed on each side must keep the equation in balance.

Nevertheless, the results from this study suggest that the misconceptions underlying specific persistent errors are not corrected through typical instruction and may require additional intervention in order for students to learn correct strategies, whether it be through interventions targeting individual misconceptions, or curricula generally aimed at improving conceptual understanding throughout the course (e.g., Cai, Moyer, Wang, \& Bikai, 2011; Booth, Oyer, PareBlagoev, Elliot, Barbieri, Augustine, \& Koedinger, under review). Results from the present study also indicate that some errors are more pernicious than others. In particular, it appears that students who make mathematical properties and operation errors on easy to moderate content, those who make variable errors (such as combining unlike terms) when solving early equations, and those who are still making equality/inequality and negative sign errors on more complex problems will have the most trouble succeeding in Algebra I. These errors, and their underlying misconceptions, may perhaps be the most important targets for intervention in and out of the classroom.

\section{ACKNOWLEDGEMENTS}

Funding for this research was provided by the Goldman Sachs Foundation, and by the Institute of Education Sciences, U.S. Department of Education, through Grant R305A100150 to the Strategic Education Research Partnership. The opinions expressed are those of the authors and do not represent views of the Institute or the U.S. Department of Education.

A preliminary version of this work was presented at the annual research conference for the National Council for Teachers of Mathematics in New Orleans, LA. Thanks are due to Arlington Public School District, Madison Metropolitan School District, Shaker Heights School District, Evanston-Skokie School District, and Evanston Township School District-collaborators in the described study.

\section{REFERENCES}

Adelman, C. (2006). The toolbox revisited: Paths to degree completion from high school through college. Washington, DC: U.S. Department of Education.

Altiparmak, K., \& Özdoğan, E. (2010). A study on the teaching of the concept of negative numbers. International Journal of Mathematical Education in Science and Technology, 41(1), 31-47. http://dx.doi.org/10.1080/00207390903189179
ACT, Inc. (2014). EXPLORE. Iowa City, IA: ACT, Inc.

Ashlock, R. B. (2006). Error patterns in computation: Using error patterns to improve instruction (9th ed.). Upper Saddle Ridge, NJ: Pearson Merrill Prentice Hall.

Askey, R. (1999). The third mathematics education revolution. Contemporary Issues in Mathematics Education, 36, 95-107.

Baroody, A. \& Ginsburg, H. (1983). The effects of instructions on children's understanding of the equals sign. The Elementary School Journal, 84(2), 199-212. http://dx.doi.org /10.1086/461356

Belenky, D. M., \& Nokes, T. J. (2009). Examining the role of manipulatives and metacognition on engagement, learning, and transfer. The Journal of Problem Solving, 2(2), 102-129. http://dx.doi.org/10.7771/1932-6246.1061

Birenbaum, M., Kelly, A. E., \& Tatsuoka, K. K. (1992). Diagnosing knowledge states in algebra using the rule space model (No. ETS-RR-92-57-ONR). Educational Testing Service: Princeton, NJ.

Booth, J. L., \& Koedinger, K. R. (2008). Key misconceptions in algebraic problem solving. In B. C. Love, K. McRae, \& V. M. Sloutsky (Eds.), Proceedings of the 30th Annual Cognitive Science Society (pp.571-576). Austin, TX: Cognitive Science Society.

Booth, J. L., \& Koedinger, K. R. (2012). Are diagrams always helpful tools? Developmental and individual differences in the effect of presentation format on students' solutions of algebra problems. British Journal of Educational Psychology, 82(3), 492-511. http://dx.doi.org /10.1111/j.2044-8279.2011.02041.x

Booth, J. L., Lange, K. E., Koedinger, K. R., \& Newton, K. J. (2013). Using example problems to improve student learning in algebra: Differentiating between correct and incorrect examples. Learning and Instruction, 25, 24-34. http://dx.doi.org/10.1016/j.learninstruc.2012.11.002

Booth, J. L., \& Newton, K. J. (2012). Fractions: Could they really be the gatekeeper's doorman? Contemporary Educational Psychology, 37(4), 247-253. http://dx.doi.org /10.1016/j.cedpsych.2012.07.001

Booth, J. L., Newton, K. J., Twiss-Garrity, L. (2014). The impact of fraction magnitude knowledge on algebra performance and learning. Journal of Experimental Child Psychology, 118, 110-118. http://dx.doi.org/10.1016/j.jecp.2013.09.001

Booth, J. L., Oyer, M. H., Paré-Blagoev, E. J., Elliot, A., Barbieri, C. Augustine, A. A., \& Koedinger, K. R. (under review). Learning algebra by example in real-world classrooms. Journal of Research on Educational Effectiveness.

Brown, T., Eade, F., \& Wilson, D. (1999). Semantic innovation: Arithmetical and algebraic metaphors within narratives of learning. Educational studies in mathematics, 40(1), 53-70. http://dx.doi.org/10.1023/A:1003738611811

Bush, S. B., \& Karp, K. S. (2013). Prerequisite algebra skills and associated misconceptions of middle grade students: 
A review. The Journal of Mathematical Behavior, 32(3), 613-632. http://dx.doi.org/10.1016/j.jmathb.2013.07.002

Cai, J., Moyer, J. C., Wang, N., \& Bikai, N. (2011). Examining students' algebraic thinking in a curricular context: A longitudinal study. In J. Cai \& E. Knuth (Eds.), Early algebraization (pp. 161-185). Berlin: Springer-Verlag. http:// dx.doi.org/10.1007/978-3-642-17735-4_11

California Department of Education. (2014). 2013 STAR test results: State of California. Retrieved from http://star.cde .ca.gov/star2013/

Cangelosi, R., Madrid, S., Cooper, S., Olson, J., \& Hartter, B. (2013). The negative sign and exponential expressions: Unveiling students' persistent errors and misconceptions. The Journal of Mathematical Behavior, 32(1), 69-82. http://dx.doi.org/10.1016/j.jmathb.2012.10.002

Carpenter, T. P., Levi, L., \& Farnsworth, V. (2000). Building a foundation for learning algebra in the elementary grades. In Brief, 1(2), 3-8.

Chesney, D. L. \& McNeil, N. M. (2014). Activation of operational thinking during arithmetic practice hinders learning and transfer. The Journal of Problem Solving, 7(1), Article 4. Retrieved from http://docs.lib.purdue.edu/jps/vol7/iss1/4

Clement, J. (1982). Algebra word problem solutions: Thought process underlying a common misconception. Journal for Research in Mathematics Education, 13(4), 16-30. http:// dx.doi.org/10.2307/748434

Confrey, J., \& Lanier, P. (1980). Students' mathematical abilities: A focus for the improvement of teaching general mathematics. School Science and Mathematics, 80(7), 549-556. http://dx.doi.org/10.1111/j.1949-8594.1980.tb09733.x

Corder, S.P. (1982). Error analysis \& interlanguage. Oxford: Oxford University Press.

Cummins, J., Malloy C., McClain, K., Mojica, Y, \& Price, J. (2006). Algebra concepts and applications. Columbus, $\mathrm{OH}$ : Glencoe/McGraw-Hill.

Empson, S. B., \& Levi L. (2011). Extending children's mathematics: Fractions and decimals. Portsmouth, NH: Heinemann.

Filloy, E., \& Rojano, T. (1989). Solving equations: The transition from arithmetic to algebra. For the Learning of Mathematics, 9(2), 19-25.

Fueyo, V., \& Bushell, D. (1998). Using number-line procedures and peer tutoring to improve the mathematics computation of low-performing first graders. Journal of Applied Behavioral Analysis, 31(3), 417-430. http:// dx.doi.org/10.1901/jaba.1998.31-417

Higgins, L. (2008, May 27). Algebra 1 stumping high school freshmen: Class of 2011 confronts tougher state requirements. Detroit Free Press.

Illinois State Board of Education. (2009). Illinois Standards Achievement Test: Grade 8 Math.

Kieran, C. (2007). Learning and teaching of algebra at the middle school through college levels: Building meaning for symbols and their manipulation. In F. K. Lister (Ed.), Second handbook of research on mathematics teaching and learning (pp. 707-762). Reston, VA: NCTM.

Kitt, N., \& Leitze, R. (1992). Using homemade algebra tiles to develop algebra and prealgebra concepts. Mathematics Teacher, 93(6), 462-466.

Knuth, E., Alibali, M. W., Weinberg, A., McNeil, N., \& Stephens, A. (2005). Middle school students' understanding of core algebraic concepts: Equality \& variable. Zentralblatt für Didaktik der Mathematik (International Reviews on Mathematical Education), 37(1), 68-76. http://dx.doi.org/10.1007/BF02655899

Knuth, E. J., Stephens, A. C., McNeil, N. M. \& Alibali, M. W. (2006). Does understanding the equal sign matter? Evidence from solving equations. Journal for Research in Mathematics Education, 37, 297-312.

Ko, Y. Y., \& Karadag, Z. (2013). Fostering middle school students' relational thinking of the equal sign using GeoGebra. Mevlana International Journal of Education, 3(3), 45-49. http://dx.doi.org/10.13054/mije.si.2013.05

Larson, R., Boswell, L., Kanold, T. D., \& Stiff, L. (2007). Algebra 1. Dallas, TX: McDougal Littell.

Leiva, M. A., Brown, R. G., \& Coes, L. (1997). Algebra 1: Explorations and applications. Evanston, IL: McDougal Littell. Liebenberg, R. (1997). The usefulness of an intensive diagnostic test. In P. Kelsall \& M. de Villiers (Eds.), Proceedings of the Third National Congress of the Association for Mathematics Education of South Africa: Vol. 2 (pp. 72-79). Durban, South Africa: University of Natal.

Lucariello, J., Tine, M. T., \& Ganley, C. M. (2014). A formative assessment of students' algebraic variable misconceptions. The Journal of Mathematical Behavior, 33, 30-41. http://dx.doi.org/10.1016/j.jmathb.2013.09.001

Matthews, P., Rittle-Johnson, B., McEldoon, K., \& Taylor, R. (2012). Measure for measure: What combining diverse measures reveals about children's understanding of the equal sign as an indicator of mathematical equality. Journal for Research in Mathematics Education, 43(3), 316350. http://dx.doi.org/10.5951/jresematheduc.43.3.0316

McNeil, N. M., Fyfe, E. R., Petersen, L. A., Dunwiddie, A. E., \& Brletic-Shipley, H. (2011). Benefits of practicing $4=2+2$ : Nontraditional problem formats facilitate children's understanding of mathematical equivalence. Child development, 82(5), 1620-1633. http://dx.doi.org /10.1111/j.1467-8624.2011.01622.x

Murdock, J., Kamischke, E., \& Kamischke, E. (2007). Discovering algebra: An investigative approach. Emeryville, CA: Key Curriculum Press.

National Governors Association Center for Best Practices \& Council of Chief State School Officers (2010). The common core state standards (mathematics). Washington, D.C.: National Governors Association Center for Best Practices \& Council of Chief State School Officers. 
National Mathematics Advisory Panel. (2008). Foundations for success: The final report of the National Mathematics Advisory Panel. Washington, DC: U.S. Department of Education.

Nesher, P. (1987). Towards an instructional theory: The role of student's misconceptions. For the Learning of Mathematics, 7(3), 33-40.

Ohio Department of Education. (2006). Ohio Achievement Tests (8) Mathematics Student Test Booklet.

Payne, S. J., \& Squibb, H. R. (1990). Algebra mal-rules and cognitive accounts of error. Cognitive Science, 14(3), 445481. http://dx.doi.org/10.1207/s15516709cog1403_4

Pennsylvania Department of Education. (2011). 2011 Keystone Exams State Summary Report-Algebra I.

Ross, A., \& Willson, V. (2012). The effects of representations, constructivist approaches, and engagement on middle school students' algebraic procedure and conceptual understanding. School Science and Mathematics, 112(2), 117128. http://dx.doi.org/10.1111/j.1949-8594.2011.00125.x

Seng, L. K. (2010). An error analysis of Form 2 (Grade 7) students in simplifying algebraic expressions: A descriptive study. Electronic Journal of Research in Educational Psychology, 8(1), 139-162.

Siegler, R. S., Duncan, G. J., Davis-Kean, P. E., Duckworth, K., Claessens, A., Engel, M., . . Chen, M. (2012). Early predictors of high school mathematics achievement. Psychological Science, 23(7), 691-697. http://dx.doi.org/10.1177 /0956797612440101

Swan, M. (2000). Making sense of algebra. Mathematics Teaching, 171, 16-19.

Tatsuoka, K. K. (1983). Rule-space: An approach for dealing with misconceptions based on item response theory.
Journal of Educational Measurement, 20(4), 34-38. http:// dx.doi.org/10.1111/j.1745-3984.1983.tb00212.x

Uttal, D. H., Scudder, K. V., \& DeLoache, J. S. (1997). Manipulatives as symbols: A new perspective on the use of concrete objects to teach mathematics. Journal of Applied Developmental Psychology, 18(1), 37-54. http://dx.doi.org /10.1016/S0193-3973(97)90013-7

Virginia Department of Education. (2008). Standards of Learning Test: Grade 8 Mathematics.

Vlassis, J. (2002). The balance model: Hindrance or support for the solving of linear equations with one unknown. Educational Studies in Mathematics, 49(3), 341-359. http:// dx.doi.org/10.1023/A:1020229023965

Vlassis, J. (2004). Making sense of the minus sign or becoming flexible in 'negativity.' Learning and Instruction, 14(5), 469484. http://dx.doi.org/10.1016/j.learninstruc.2004.06.012

Wagenmakers, E. J. (2007). A practical solution to the pervasive problems of $p$ values. Psychonomic Bulletin and Review, 14(5), 779-804. http://dx.doi.org/10.3758/BF03194105

WeWantToKnow. (2012). DragonBox Algebra 5+. http:// dragonboxapp.com/

Wisconsin Department of Public Instruction. (2006). Wisconsin Knowledge and Concepts Examinations CriterionReferenced Test: Guide to Grade 8 Released Item Books in Reading and Mathematics.

Yerushalmy, M. (1997). Mathematizing verbal descriptions of situations: A language to support modeling. Cognition and Instruction, 15(2), 207-264. http://dx.doi.org/10.1207 /s1532690xci1502_3 